\title{
Performance Analysis and Visualization of Canard and Fuselage Effects on Flow Patterns around a Straight-Body-Type-Fuselage (SBTF) Fighter Models with Experimental Method in Water Tunnel
}

\author{
Sutrisno ${ }^{1}$, Firdaus RS $^{1}$, Zainuri A ${ }^{1}$, Sigit Iswahyudi ${ }^{1,2} \&$ Setyawan Bekti Wibowo ${ }^{1,3}$ \\ ${ }^{1}$ Department of Mechanical and Industrial Engineering, Faculty of Engineering, Universitas Gadjah Mada, \\ Yogyakarta 55281, Indonesia \\ ${ }^{2}$ Department of Mechanical Engineering, UniversitasTidar, Magelang 56116, Indonesia \\ ${ }^{3}$ Department of Mechanical, Vocational College, Universitas Gadjah Mada, Yogyakarta 55281, Indonesia \\ Correspondence: Sutrisno, Department of Mechanical and Industrial Engineering, Faculty of Engineering, \\ Universitas Gadjah Mada, Yogyakarta 55281, Indonesia.Tel: 62-8962-2669-341. E-mail: sutrisno@ugm.ac.id
}

Received: September 7, 2018

Accepted: September 25, 2018 Online Published: September 29, 2018

doi:10.5539/mas.v12n10p195

URL: https://doi.org/10.5539/mas.v12n10p195

The research is financed bythe Department of Mechanical \& Industrial Engineering, Universitas Gadjah Mada, Indonesia.

\begin{abstract}
Performance analysis and visualization of canard and fuselage effects on flow patterns around an SBTF fighter model have been conducted. An SBTF fighter model with an experimental method in a water tunnel would easily reveal visually the vortex dynamics phenomenon that occurred. Testing has been done, with some form of noncanard and canard aircraft in a water tunnel, on vortex dynamics and aerodynamic power on the aircraft model. The stream demonstration used a fluid speed of $0.1 \mathrm{~m} / \mathrm{s}$ and Reynolds number $6.577 \times 103$ on a 1:110 scale model and measured using dye injection method with a print ink type with a mixture ratio of $1: 8$. The result of the research using GAMA water tunnel showed the aerodynamic force and vortex dynamics phenomenon that happened on the model aircraft. The research on the benefits of the canard is also done by examining the performance and the flow visualization of an SBTF fighter without fuselage, with the symmetrical plane and with the regular fuselage in a water tunnel. The results showed that the use of canard affected the lift, drag, and flow pattern around the wings. The use of canard can enhance the lift of the plane and function to delay the stall by restoring the flow above the wing which should have experienced turbulence back into laminar so that the fighter can maneuver to a higher angle of attack (AoA) without stalling. It is identified that canard and fuselage play significant roles on the design of a fighter. The design choice of the fuselage and the employment of canard are fundamental to support the ability of maneuver and agility of the fighter.
\end{abstract}

Keywords: canard, symmetrical fuselage, wing, lift, drag, flow visualization, vortex breakdown, stall

\section{Introduction}

Developed countries now have strong armies, remarkably robust, highly capable fleets of fighters. Some countries develop fighter planes that have reliable maneuverability and agility. Some researches have been done on the effects of vortex dynamics, to have a high lift at high AoA, especially toward dependable agility and maneuverability.

The fuselage effect on the vortex core from the canard-main wing-body interaction has become the primary focus of this present study. Shi et al., (Shi, Deng, Wang, \& Tian, 2013) have shown that front-body eddy can suspend wing eddy interruption and the influence weakening with an increase of the AoA because of the explosion of the front-body eddy. The model in this study is a wing-body structure which include a chinned body and a moderately swept-back wing. Burst of the stronger eddy is suspend, and the outbreak of the weaker eddy is boosted. It gifts a strengthened and a reduced effect of induction on wing flow respectively. Thus, front-body eddy stream has a strong influence on vortical stream of the wing.

Sohn and Chang (Sohn, Hwan Myong \& Chang, 2010) have studied the effect of a center body on the vortex flow 
of a double-delta (double triangle) wing (DDW) with leading edge extension (LEX). The results of demonstration indicate that the occurrence of a spin of the DDW model show advanced spin interplay of the wing and LEX eddy, at least for the selected AoAof $24^{0}$. Quantitative study of pressure measurements showed the effects of a center body to be protruding for the matter with elevated AoA of angles of sideslip.

When an aircraft changed from utilizing planar wing to have swept, and delta wings (DW), wing tip vortex combine with the air passed the leading edge (LE) evolved into a rolled-up vortex and produced extra lifts. As the wing sweep increases above 55 degrees, the spanwise component of flow is robust enough to push the axial component of the vortex toward the tip creating a stable, non-expanding, cone-shaped vortex, as it is called vortex core. The vortex cores, generated by highly swept wing, would break down after some distance from the frontedge. As the AoA became high, the vortex breakdown location moved closer to thefront-edge. The burst of the eddy signified the loss of low pressure on board the DW surface, and the lift was destroyed as the DW stall occurred.

Several types of research on vortex dynamics related with the vortex break down on DW has been conducted. JinJun (Jin-Jun \& Wang, 2008) has contributed experimental study on LE eddy structures for stream over DW. Mitchel has learned vortical stream regulation and burst over slender DW. Vlahostergios(Vlahostergios, Missirlis, Yakinthos, \& Goulas, 2013) has investigated vortex breakdown control using jet flap.

Some researches on delta-wing have been reported. Kwak and Nelson has conducted vortical current supervision over DW with other sweepback angles (Kwak, Nelson, Dame, \& Dame, 2010), Miller and Williamson have done hectic structures in the wake of trailing vortex of a DW (Miller \& Williamson, 1997), Pino et al. have compared between PIV measurements and models, to construct the structure of trailing vortices(del Pino, Parras, Felli, \& Fernandez-Feria, 2011), Huang et al. have performed simulation of the sinusoidal leading edge (LE) effect on DW power and process (Chen, Pan, \& Wang, 2013).

The ability of fighters to have a high lift at high AoA, highly required to have high combat superiority and the vortex break down on DW has to be delayed, and the lift has to be amplified. There were two ways for those purposes, by employing canard wing and employing leading edge extension (LEX). Therefore, there were two types of fighter, i) fighter with LEX or double delta fighter types, and ii) fighters with a canard. Since fighter with canards was more accessible to be detected by radar, US has discontinued developing further research extensively, and focused on the fighter with LEX, followed by South Korea. Other countries, such as France, Sweden, Germany, Russia and China carry on developing both fighter types. Additional differences between LEX and Canard were that LEX itself was harder to control, where to gain controllability depended on the vectorized engine and additional extra engine. On the contrary, canard had high controllability to perform spectacular maneuvers. In this study, vortex dynamics of canard fighters would be investigated.

Numerous researches on double-delta fighters have been conducted. Abderrahmane has performed vortex structures visualization built on the upper surface of DDW, (Abene, 2013) Sun et al. have done simulations on detached stream over a 76/40 DDW (Sun, Li, \& Zhang, 2013).

Wen Jing et al. have conducted an experimental investigation of static directional stability (Jing, Yankui, \& Xueying, 2016), Lee and Su have performed wing-edge eddy supervision through the implementation of a reverse half-DW (Lee \& Su, 2012), Mahdi has completed estimation of wing downwash applying simulation (Mahdi, 2015), Lopes and Girardi have reported an investigation of the aerodynamic properties of a wingcanard arrangement with canard distorsion(Lopes \& Roberto da Mota Girardi, 2005), and Cai et al. have designed of wing-body arrangement optimization to suspend the start of asymmetrical vortex(Cai, Tsai, Luo, \& Liu, 2011). Setyawan et al. have investigated the application of water tunnel for eddy burst demonstrationon the DW (Wibowo, Sutrisno, Rohmat, et al., 2018), and completed thorough studies on turbulence models for vortex breakdown detection over DW (Wibowo, Sutrisno, \& Rohmat, 2018).

Several types of research in canard and LEX fighters tend to continue. Guoqing has investigated vortex interaction in canard-FSW. Mehdi had learned stream dynamics of a canard arranged TransCruiser. Ghoreyshi et al. simulate endorsement of static and dynamic of stream physics of a canard arranged TransCruiser (Ghoreyshi, Korkis-kanaan, Jirásek, Cummings, \& Lofthouse, 2016; Guoqing, Shuxing, \& Yong, 2010). Several types of research on canard fighters have been conducted. Ghoreyshi et al. has done fluid dynamic load simulation of X-31 fighter nodding motions (Ghoreyshi, Cummings, Ronch, \& Badcock, 2013), Samimi et al. has analyzed canard-body structure in low transonic flow (Samimi, Davari, \& Soltani, 2013), Ito and Iwashita have learned on the fluid dynamic characteristics of a canard-aircraft (Ito \& Iwashita, 2014), Schütte et al. have completed simulation andexperimentalstudy of numerical unstable stream around the X-31 models (Schütte, Rein, \& Höhler, 2007).

Even though the dissimilarity was not stated explicitly, the effect of fuselage presence was quite noticeable. Boelens(Boelens, 2012) has contributed steady flow simulations, complete with fuselage, have been performed 
employing $\mathrm{CFD}$ at $\mathrm{M}=0.18$ and $\mathrm{Re}_{\text {m.a.c. }}=2.07 \times 10^{6}$ validated using the $\mathrm{X}-31$ wind tunnel model data test conducted in a LSWT Germany. Based on these results, one could conclude that 3 eddy patterns demonstrate the inner wing vortex and the strake vortexoriginating from the wing LE merge down into a singular vortex. Chen et al.(Qu, Chen, Liu, Guo, \& Qu, 2015) have reported vortex flow over the W40C60 close-coupled canard configuration, without a fuselage, at a high AoA has been simulated using delayed detached-eddy simulation (DDES). At zero sideslip, predictions of force and pressure are in excellent agreement with several experiments. Under sideslip, important nonlinearities are discovered, and some investigations reveal the origin. In the flow visualization conducted by Chen et al. the iso-surface of instantaneous $\mathrm{Q}=2.5 \times 10^{5}$ do not reveal the curved trajectory of the vortex core passage. It showed significant difference with the results of Boelens, which reveal the curved trajectory of the vortex core passage, the inner wing and strake eddy coming from the wing LE merge and interact downstream into a single vortex. It is strongly suspected that the vortex merging was caused by the presence of the fuselage since the fuselage was a solid boundary, and a solid boundary is a source and the estuary of vortex filaments.

Sutrisno et al. have conducted the rolled-up vortices and tip eddy investigation in the simulation pattern of the 3D swept-rearward wind turbine blades (Sutrisno et al., 2017). Sutrisno et al. have completed stream demonstration simulation research of the rolled-up and body eddy effects of the Chengdu military aircraft with canard (Sutrisno et al., 2018). Since in the DDW, it does not give significant results, in this study, the effect of fuselage presence on the vortex core originating from the canard-main wing-body interaction has become the main center of attention of this analysis and would be conducted in a water tunnel facility.

Water tunnel had become essential tools to develop U.S. aeronautical research development in the past. Owen and Peake have performed vortex breakdown and control experiments in the Ames Dryden water tunnel (Owen \& Peake, 2003), Thompson has conducted visualization of vortex flows around canard configurations with highly swept LE, Johnson and Fisher has reported research results of water-tunnel of a TF/A-18 and F/A-18 canopy stream demonstration (Johnson \& Fisher, 1990), Cobleigh and Frate have done water tunnel stream demonstration research of a 4.4\% scale X-31 forebody (Cobleigh \& Delfrate, 1994), Frate has described the complete NASA Dryden flow visualization facility (Frate, 1995), Erm has shown an appraisal of the effectiveness of water tunnels for fluid dynamic study (Erm \& Ol, 2012). It is not known that the productivity of US researchers employing water tunnel, especially in investigating canard fighters slowed down significantly since fighter with canard wing hard to hide from the radar screen. We really hope that the finding of the fuselage effect difference on stall delay would give more motivations.

The fuselage effect difference on stall delay would give significant modification on stability, control, yaw, pitch, rolling and unsteady handling of the fighters. Researchers have been conducted. Following to the fuselage effect theory, canard fighters have two different fighter types, namely a) the straight body type fuselage (SBTF) fighter and b) the bird's body type fuselage (BBTF) fighter, as the head and the neck of the fighters resemblance the head and the neck of a bird. The SBTF fighters include Rafale, Eurofighter Typhoon, Chengdu J-10, SAAB Gripen.

The field data (https://aviatia.net/rafale-vs-eurofighter/) shows that Rafale and Eurofighter are well known to have very high dogfighting abilities. However, there are still more opportunities to strengthen their agility and maneuverability, which in principle is increasing their lift coefficients at high AoA. This requires in-depth research on the fighter vortex dynamic, which will determine the role of the $\mathrm{RuV}$ effect, the role of vortex cores in generating negative SPD on the right surface and reducing the losses of the lift coefficient of the fighter. In this case, the role of Q-criterion is significant.

The implementation of a water tunnel would make easier to reveal the phenomena that occur around the investigated objects. For a lengthy period, researchers employed water tunnels to see a demonstration of stream testing on inspected objects or fluid flow, especially on fighter aircraft. The vortex phenomenon of breakdown location that occurs on the DW has been observed using water tunnel. So, this study focuses on observing the effect of fuselage variations on vortex dynamics and aerodynamic performance on aircraft models similar to the SBTF fighter model using water tunnel.

\section{Method}

Stream demonstration in low-velocity water tunnels is a powerful way to analyze complex flow fields at very low Reynolds numbers. The eddy and its interconnection, and the burst in water tunnel are relatively insensitive to Reynolds number. Erickson determined that stream sectors that are Eddy-influenced are the same without paying attention to Reynolds number (Erickson, 1981). The stream sectors around the SBTF fighter arrangement at high AoA can be characterized as Eddy-influenced; so Erickson's findings give faith that the output of the test of the water tunnel is trustworthy. In this experiment, the SBTF fighter's CL and CD measurements accuracy in water 
tunnel is relatively satisfying. Water tunnel storage can accommodate 1200 liters of water, connected via a silencer tank, a contraction cone to the test section with a $200 \mathrm{~mm} \times 200 \mathrm{~mm}$ cross-section. The silencer or tranquilizer tanks contain fibers and nets to stabilize the flow as it passes through the test section. Before entering the test section, water flows through two honeycombs to allow the flow to flow laminar.

\subsection{Identify Subsections}

Data collection was carried out at GAMA Water Tunnel at the UGM fluid dynamics laboratory. GAMA Water Tunnel has been validated according to standards for use in testing and has been published. GAMA Water Tunnel images as shown in Fig. 1.
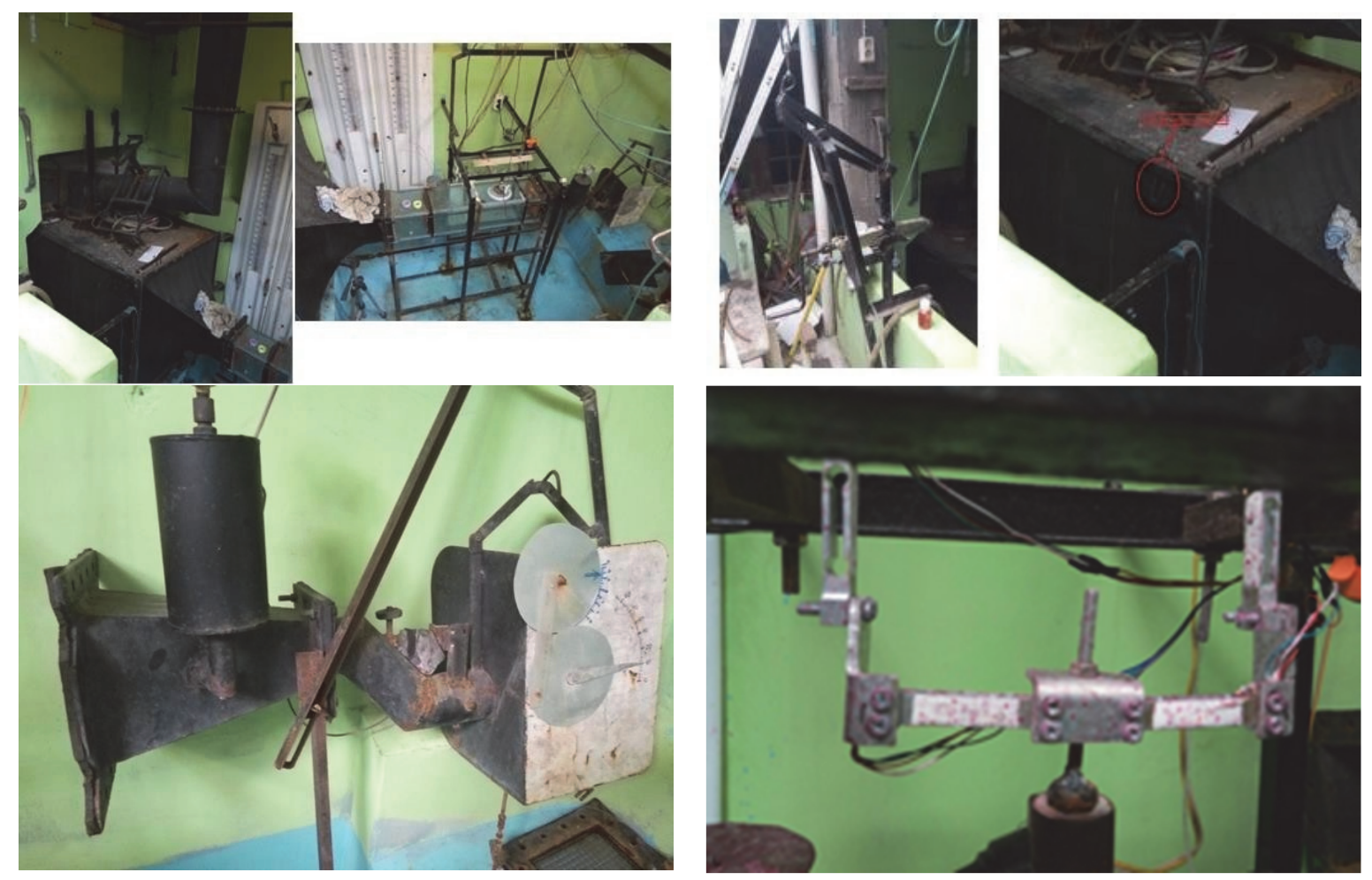

Figure 1. GAMA Water Tunnel applied on the research, and flow controllers in Water tunnel

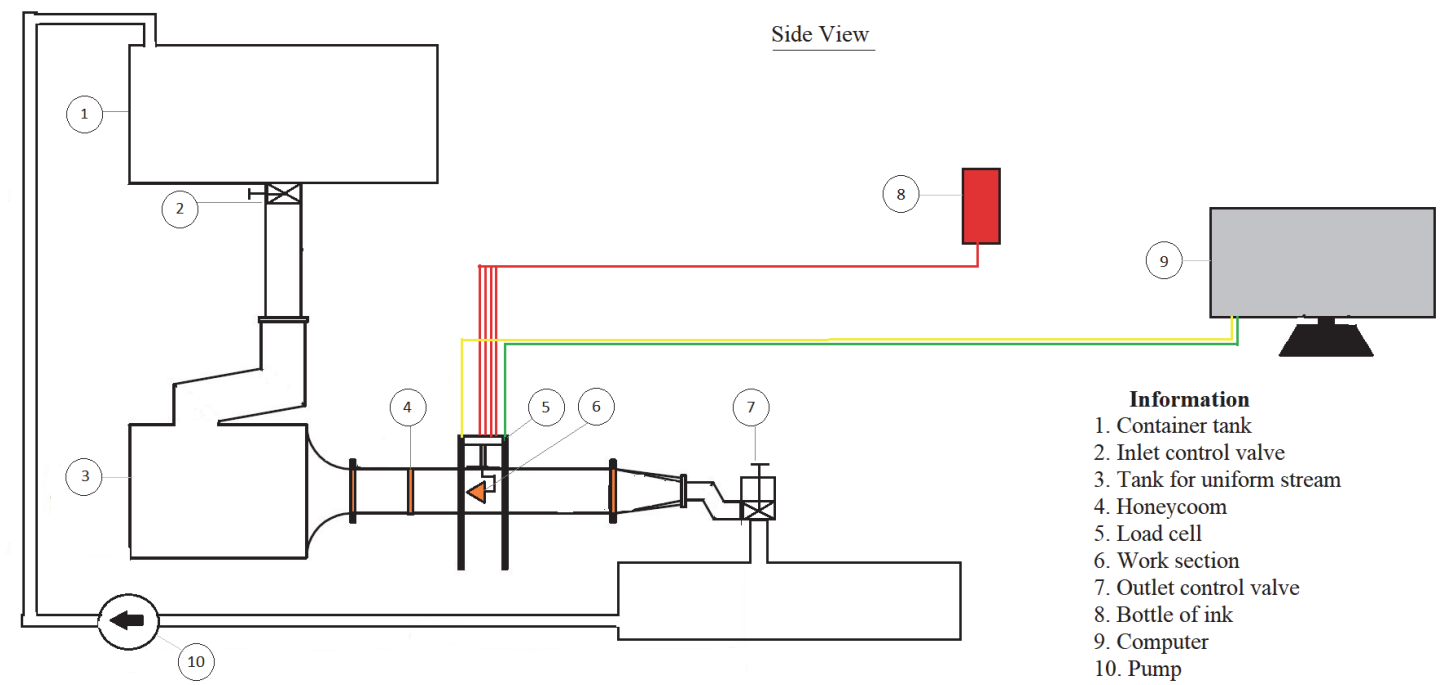

Figure 2. Schematic flow in Gama Water Tunnel 
GAMA Water Tunnel has a 1200 liters water storage pool and has a maximum test section specification of 200 $\mathrm{mm} \times 200 \mathrm{~mm}$. Water is channeled to the flow reducer tank, in which there are fibers and nets used to stabilize the flow to obtain low-turbulence flow when passing the test section. The water pressure in the tank is always kept equal to atmospheric pressure. Then the water will move through two honeycombs. The flow into the water tunnel is awaited until it is stable. The flow through the pressure controller hole is stabilized. Then the speed is adjusted to fine-tune the desired speed.

\subsection{Three-Dimensional Modeling}
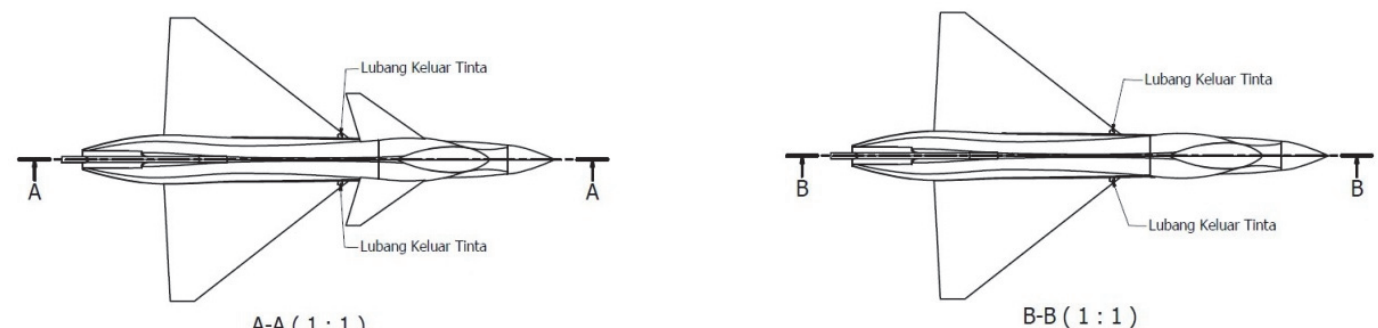

A-A $(1: 1)$
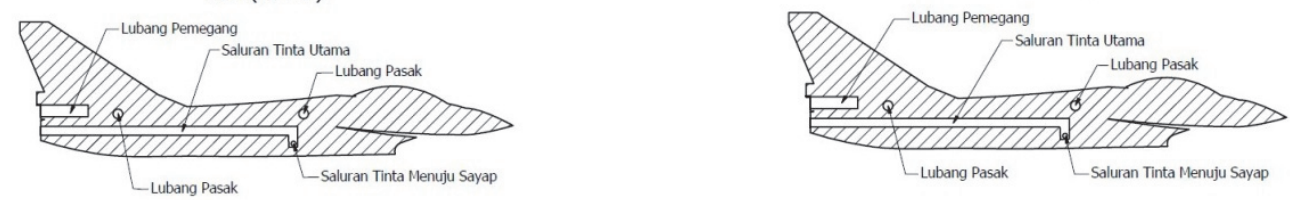

a. Channels in the first aircraft model

b. Channels in the second aircraft model (model without canard)

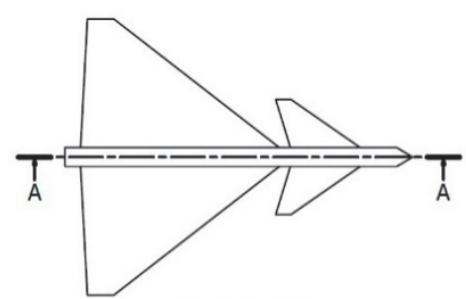

A-A ( $1: 1)$

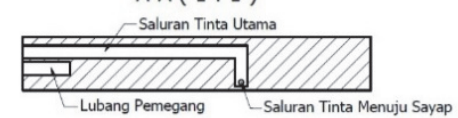

c.Channels in the second aircraft additional model

(with wall symmetry model)

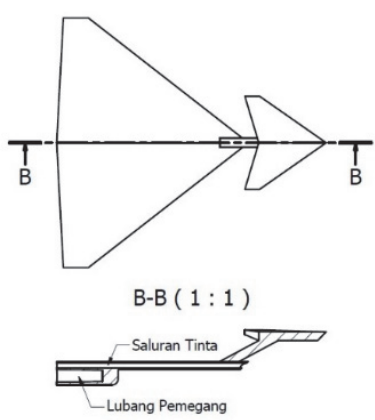

d. Channels in the third aircraft additional model (model without fuselage)

Figure 3. SBTF fighter model

The length of the overall fighter model is scaled to a length of $17 \mathrm{~cm}$ to adjust the width and the height to fit the test section channel. The clearance of model space is quite extensive at the time of testing with varying angles. The tested model consists of 2 types; 1 . The first model is in the form of an original and 2. The second model without canard.The 3 additional models consist of a) the first additional model is a $17 \mathrm{~cm}$ SBTF fighter, b) the second additional model is an SBTF with symmetrical walls $0.6 \mathrm{~cm}$ thick $1.7 \mathrm{~cm}$ long and $11 \mathrm{~cm}$ long, and c) the third additional model of SBTF without the fuselage. The specifications of the SBTF fighter model illustrated in Fig. 3 consist of a) the chord length in root canard is $22.86 \mathrm{~mm}$, the chord length on the canard tip is $4,809 \mathrm{~mm}$, and the canard length on one side $16 \mathrm{~mm}$.

\section{Results and Discussion}

\subsection{Visualization Results in Analysis of All of 3 Additional Models of SBTF Fighter Configuration}

Figure 4.a to 4.dshow the visualization of flow in SBTF fighter model with the original fuselage, symmetric wall fuselage and without the fuselage as well as with and without canard. Vortex core formation, vortex breakdown and fuselage vortex that occur above the canard surface, main wing, and body on aircraft models similar to in SBTF fighter original fuselage model. Vortex core on canard and main wing start to form in AoA around $15^{\circ}$. Whereas in low AoA, only a flow line is called streamline. Based on the video of the test results that have been observed, the increase in AoA will cause a difference in the flow velocity between the upper surface of the wing 
and under the wing. The flow velocity above the wing surface will be higher than the flow velocity below the wing. This condition will cause the formation of the rolled-up vortex from the tip of the wing to the downstream of the wing which in the middle part of the coil there is a vortex core or also called the vortex core which has the lowest pressure. This vortex core has a higher speed than the freestream speed. Thus, the vortex core makes negative pressure above the wing surface. The formation of a vortex core indicates the lift force that occurs.

In low AoA, vortex core and vortex breakdown have not been seen. In the original fuselage model, Fig. 4, the vortex core above the main wing surface began to be seen in AoA $15^{\circ}$ and breakdown about full of the wing length of the chord. At AoA $25^{\circ}$, the location of the breakdown vortex occurred about $61.5 \%$ of the wing length of the chord. At AoA $35^{\circ}$, the location of the breakdown vortex is at $26.7 \%$ of the wing chord. Every increase in AoA causes the location of the breakdown vortex to move further towards the top of the wing.

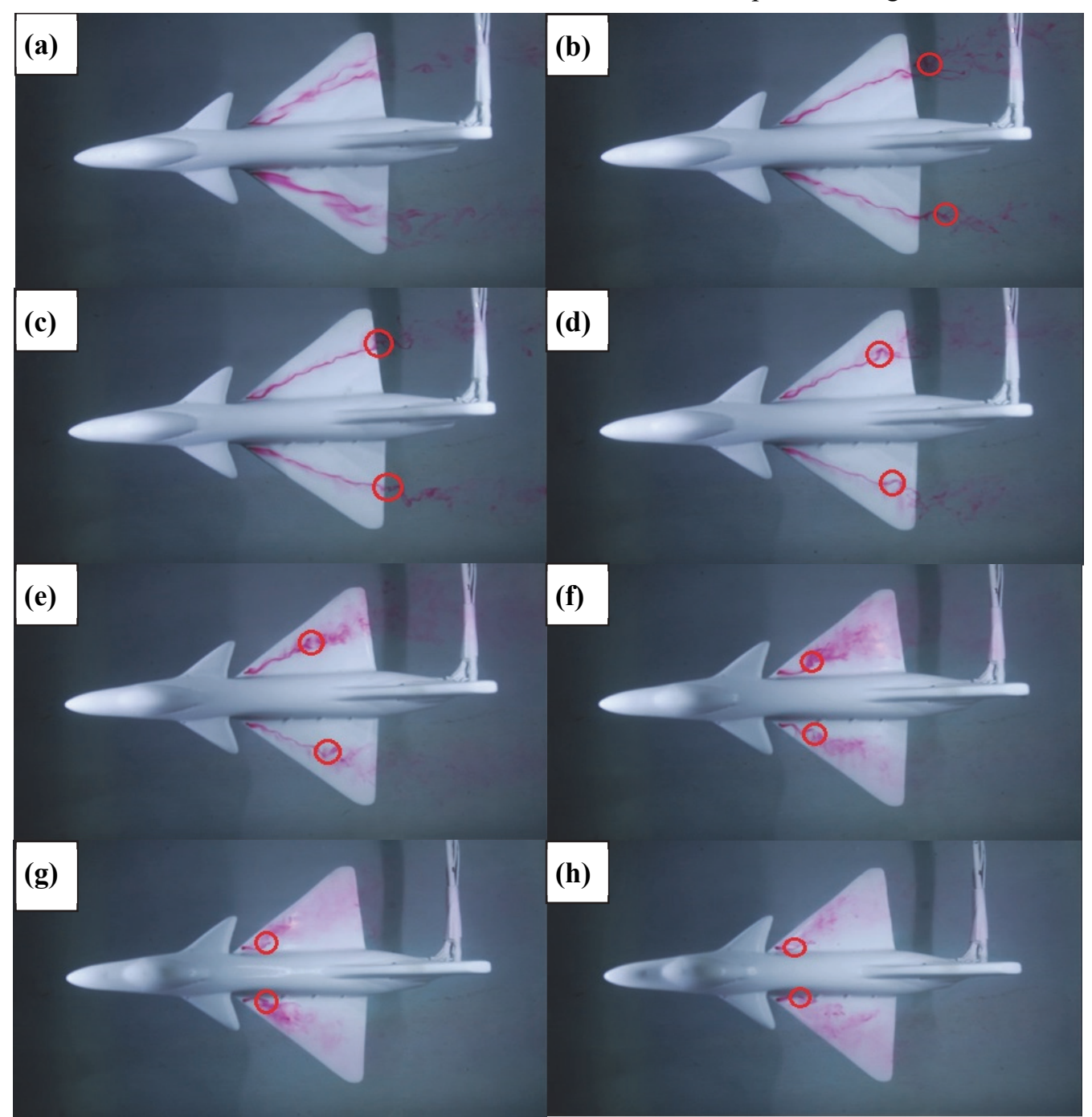

Figure 4. Visualization Results of Additional Models of SBTF Fighter Configuration Type 1 at AoA $=\left(\right.$ a) $0^{\circ}$ (b) $10^{\circ}$ (c) $15^{\circ}$ (d) $20^{\circ}$ (e) $25^{\circ}$ (f) $30^{\circ}$ (g) $35^{\circ}$ (h) $40^{\circ}$

At a high AoA of about $20^{\circ}$ to $35^{\circ}$, vortex core tends to move away from the LE and is attracted towards the fuselage. This condition is caused by the interaction between the vortex core on the wing and the fuselage vortex so that the vortex core is attracted to the fuselage area. Whereas in small AoA, the vortex core that forms is along the LE.In the symmetric fuselage wall model, Fig. 5, when the model is in low AoA conditions around $5^{\circ}$ to $20^{\circ}$, the vortex core is formed above the canard surface, and the main wing moves along the LE. However, when AoA is high, the vortex core starts to be drawn towards the fuselage wall. This condition is caused by the interaction between fuselage vortex which is formed because of the boundary wall with canard vortex and playing vortex wing, resulting in a combination of the vortex. Fuselage vortex makes a negative pressure on the symmetrical wall so that the vortex coreis pulled towards the fuselage wall. At AoA $20^{\circ}$, the location of the breakdown vortex is 
around $27.6 \%$ of the wing length of the wing chord. In this model, vortex damage occurs so fast that at AoA $35^{\circ}$, the vortex breakdown location is $77 \%$ close to the top of the wing.
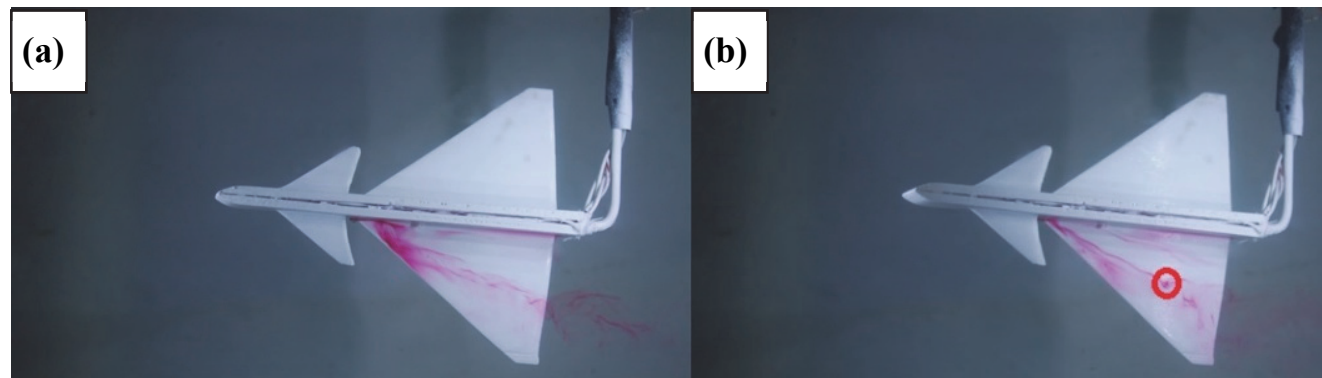
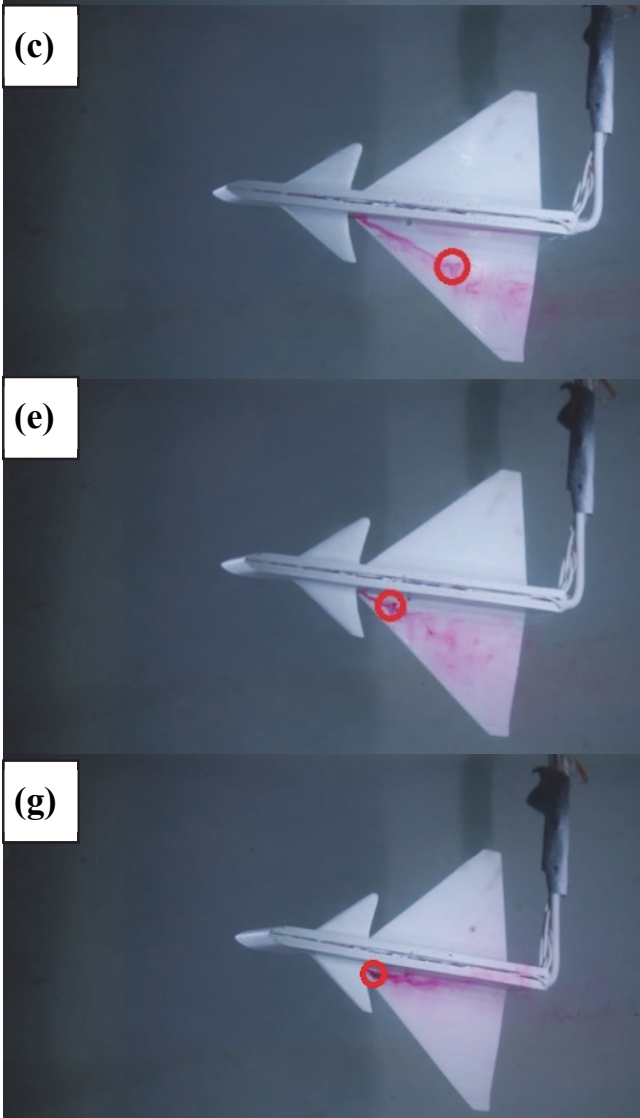
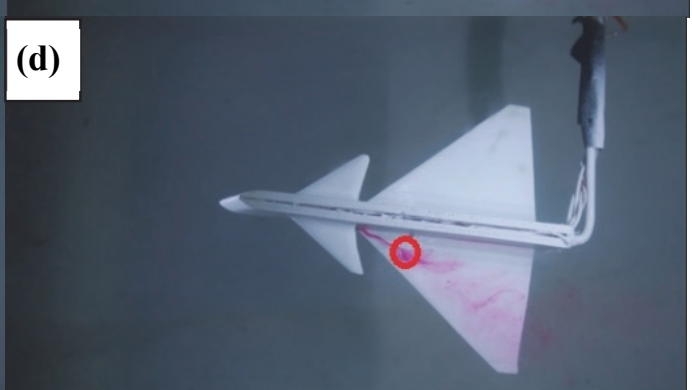

(f)

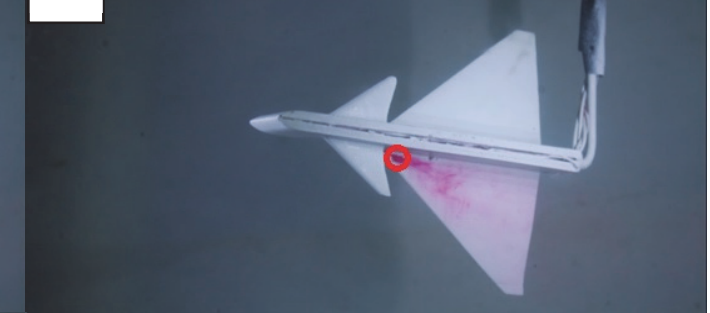

(h)

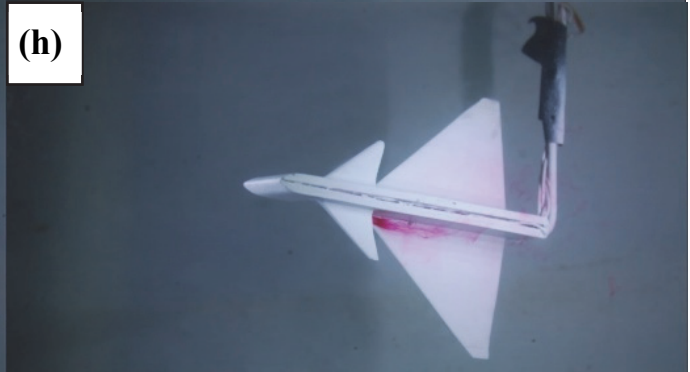

(b)

$10^{\circ}$ (c) $15^{\circ}$

(d) $20^{\circ}$

(e) $25^{\circ}$

(f) $30^{\circ}$

(g) $35^{\circ}$

(h) $40^{\circ}$

In the SBTF fightermodel without fuselage, Fig. 6, the formation of vortex cores is more accessible and more precise. At AoA $20^{\circ}$, the vortex core length is still around $98 \%$ of the wing chord's length. While at AoA $25^{\circ}$ the length of the formed vortex core is still around $75 \%$ of the wing length of the wing chord. In this model, the damage to the vortex core occurs more slowly than each increase in AoA compared to the model with the fuselage, so that at AoA high $30^{\circ}$ vortex core still forms about $56.8 \%$ of the wing length. In models without fuselage, vortex cores that occur above the wing from low to high AoA flow around the LE. This is due to the absence of two vortex interactions so that the vortex flow only goes in one direction.

\subsection{Visualization Results of SBTF Fighter without Canard}

From the results of the observation of the visualization results, Fig. 7, it can be concluded that as long as there is laminar flow attached to the wing, there is still a lift that works on the wing. Then after the flow completely separates there is no laminar flow attached to the wing, there has been a stall on the aircraft model. Stall events are the event of loss of the lift on the plane. For the non-canard fighter, there is a difference in the AoA where the two 
models experience stall. The first model stalled at 45 degrees, the second model that does not use canard experiences a stall at an AoA of 40 degrees. Canard use can maintain a higher AoA lift.

According to existing theories, one of the functions of using canard on a plane is to increase lift on the aircraft and serves to delay the stall on the aircraft by firing a high-speed laminar flow vortex towards the wing, so that it remains laminar. With the ability to maintain lift (lift), the aircraft is able to maneuver up to a high AoA.

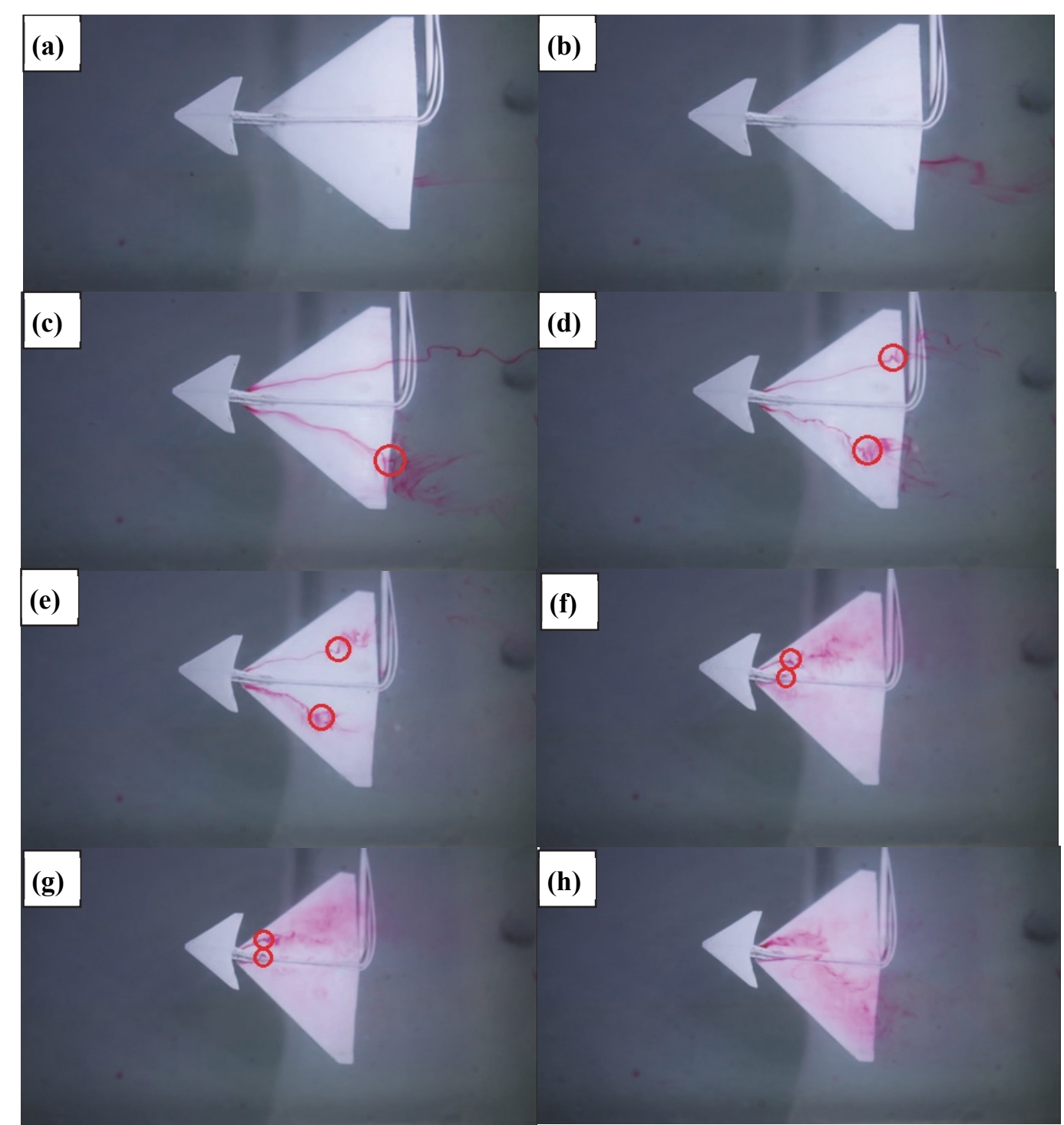

Figure 6. Visualization Results of Additional Models of SBTF Fighter Configuration Type 3 at AoA $=$ (a) $0^{\circ}$ (b) $10^{\circ}$ (c) $20^{\circ}$ (d) $25^{\circ}$ (e) $30^{\circ}$ (f) $35^{\circ}$ (g) $40^{\circ}$ (h) $45^{\circ}$ 


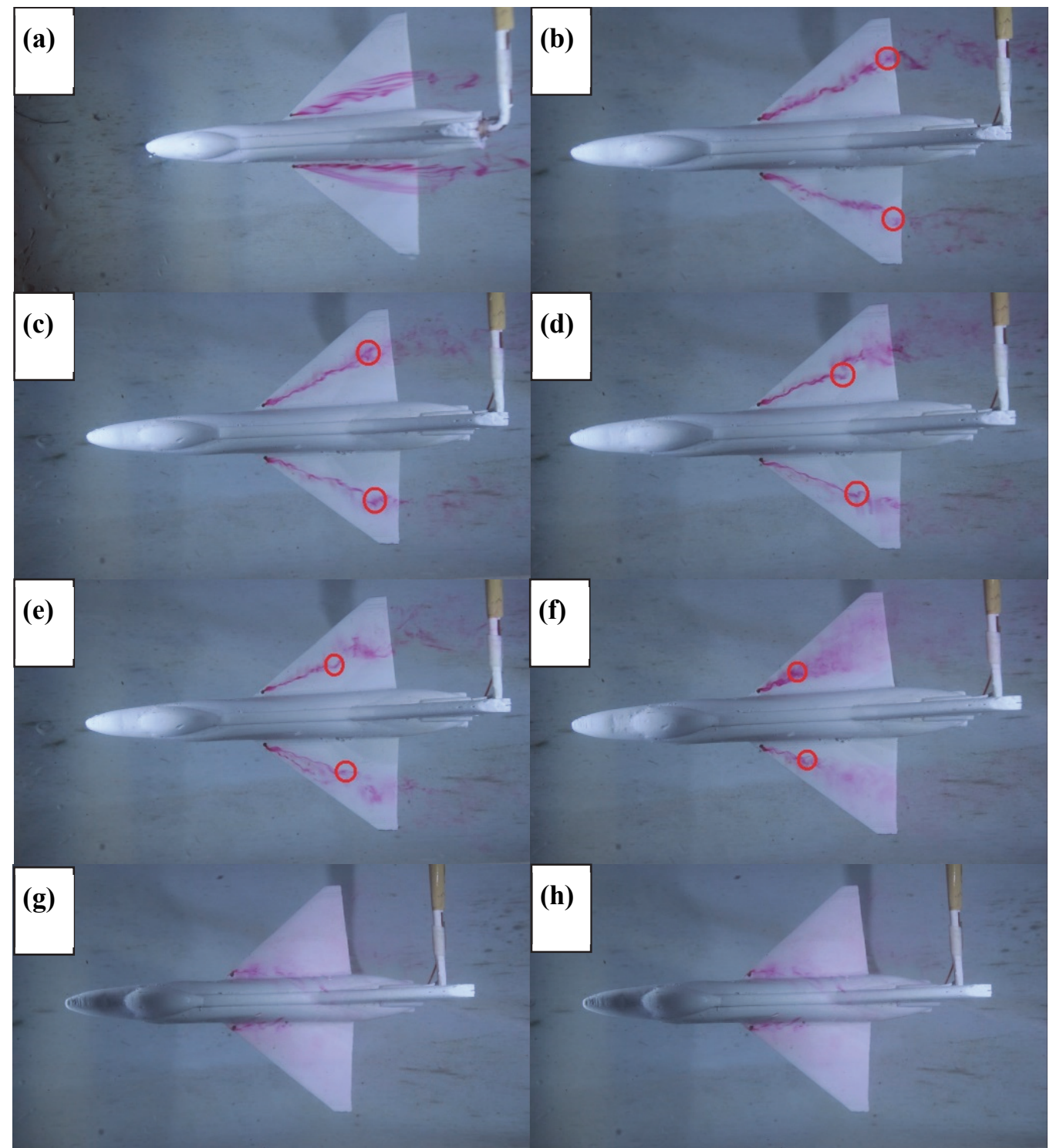

Figure 7. Visualization Results of SBTF Fighter without Canard at AoA $=\left(\right.$ a) $0^{\circ}$ (b) $10^{\circ}$ (c) $15^{\circ}$ (d) $20^{\circ}$ (e) $25^{\circ}$ (f) $30^{\circ}$ (g) $35^{\circ}$ (h) $40^{\circ}$

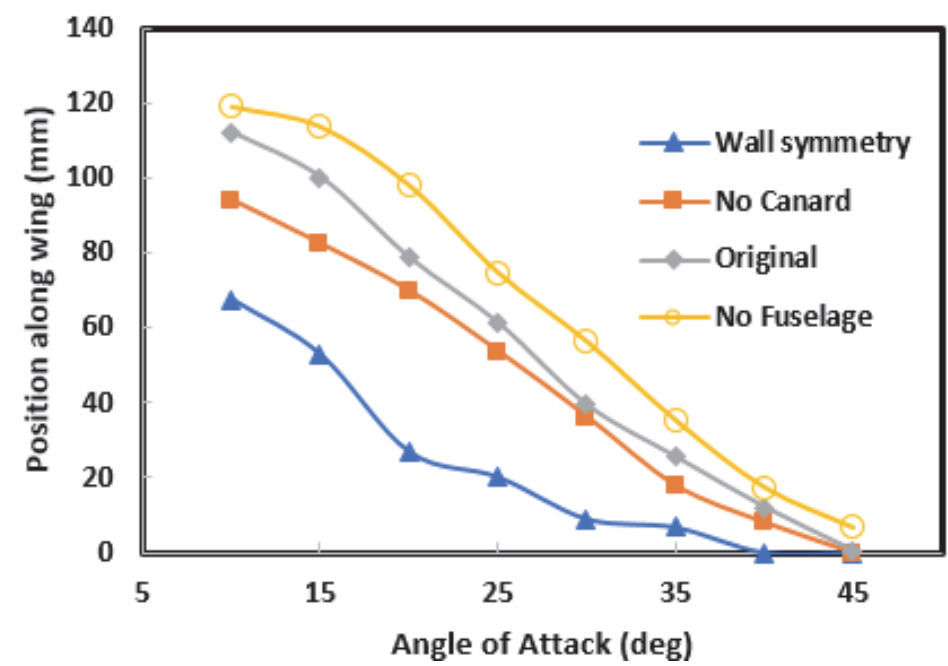

Figure 8. Vortex-core breakdown location of all 3 additional and without canard models of SBTF fighter configuration 


\subsection{Vortex-core Breakdown Location of all 3 Additional Models of SBTF Fighter Configuration}

Figure 8 shows the location of the vortex breakdown of the AoA increase in each test model. At low angles, the original fuselage model has a vortex breakdown location that is farther than the symmetric fuselage and without fuselage walls, but at AoA the high breakdown vortex location is relatively the same.

Table 1. The length of vortex core of all 3 additional and without canard models of SBTF fighters.

\begin{tabular}{lllll}
\hline $\begin{array}{l}\text { AoA } \\
\text { (degree) })\end{array}$ & $\begin{array}{l}\text { Model 1 } \\
\text { (time wing length) }\end{array}$ & $\begin{array}{l}\text { Additional Model 2 } \\
\text { (time wing length) }\end{array}$ & $\begin{array}{l}\text { Additional Model 3 } \\
\text { (time wing length) }\end{array}$ & $\begin{array}{l}\text { Model no-canard } \\
\text { (time wing length }\end{array}$ \\
\hline 0 & - & - & - & \\
10 & 112.5 & 68.3 & 118.7 & 94.1 \\
15 & 100 & 53.3 & 113.7 & 82.4 \\
20 & 78.6 & 27.6 & 98 & 70.6 \\
25 & 61.5 & 21.1 & 75 & 53.9 \\
30 & 39.3 & 8.8 & 56.8 & 38 \\
35 & 26.7 & 7.7 & 36.3 & 18.8 \\
40 & 12.1 & 0 & 18.2 & 8 \\
45 & 0 & 0 & 7.7 & 0 \\
\hline
\end{tabular}

\subsection{Measurement results of Lift and Drag on SBTF Fighter for All 3 Additional Models}

If the $\mathrm{C}_{\mathrm{Lmax}}$ value of the three aircraft models is observed, then the influence of the use and selection of the fuselage model on aircraft performance is obtained. The first model has a $\mathrm{C}_{\mathrm{Lmax}}$ value higher than the other two models. This shows that use of fuselage with the right design can increase style from airplanes.

Figure 9.a.and 9.b. show the differences in $C_{L}$ and $C_{D}$ values produced between the three original fuselage aircraft models, symmetric wall fuselage and without the fuselage. The highest maximum $\mathrm{C}_{\mathrm{L}}$ value occurs in the original fuselage type model at AoA $40^{\circ}$ around 1.20. This is because the fuselage formation in the original fuselage model causes the formation of a fuselage vortex roll up so that the vortex core on the main wing is drawn towards the fuselage body. The SBTF fighter model has a straight fuselage, which creates a negative pressure on the body surface that causes lift. However, on the symmetric fuselage wall model, vortex cores that are attracted to the body cause a loss of $C_{L}$ value because of the fuselage shape which is like a symmetrical wall, so that the lift force occurs perpendicular to the wall which causes the aircraft to be unstable. Whereas in the model without fuselage, the $\mathrm{C}_{\mathrm{L}}$ value is generated entirely by the wing without any influence from the fuselage. The value of $C_{L}$ without fuselage is almost the same as the symmetric wall fuselage, but at high AoA the $\mathrm{C}_{\mathrm{L}}$ value on the model without fuselage is greater.The original and wall symmetry models have $C_{D} s$ higher than the one that has no fuselage due to body influence.

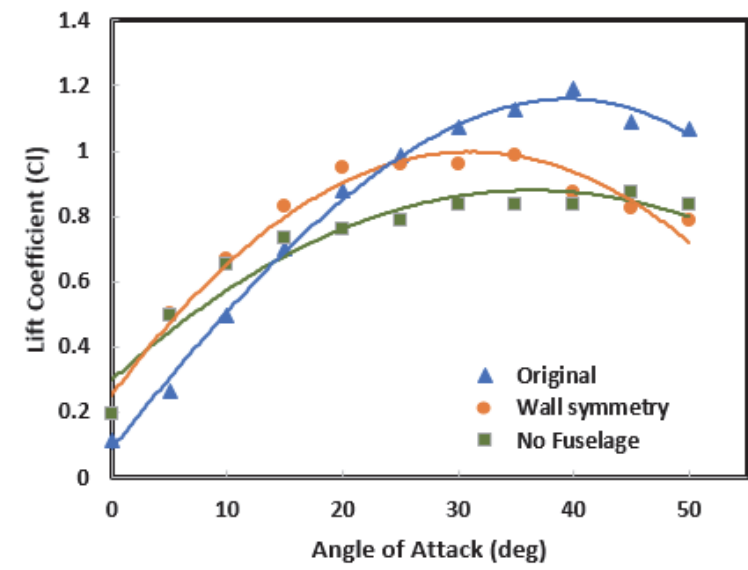

(a) Lift coefficient $\left(\mathrm{C}_{\mathrm{L}}\right)$

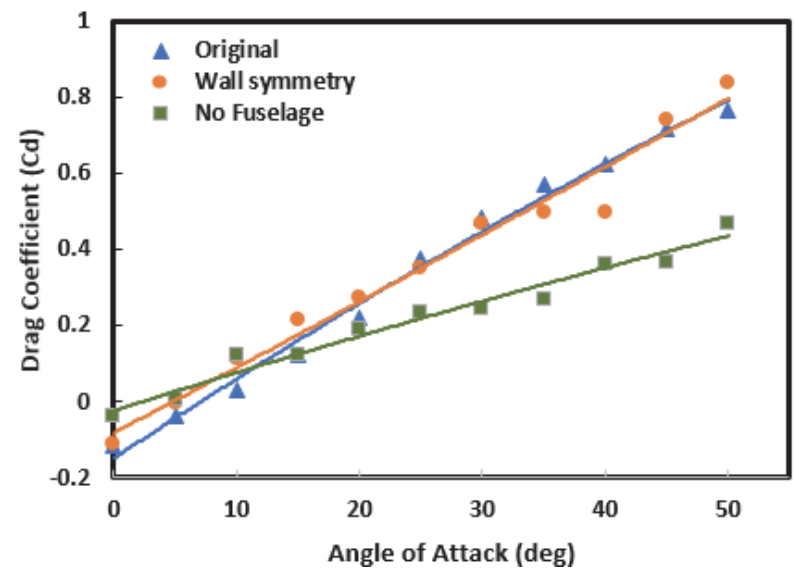

(b) Drag coefficient $\left(C_{D}\right)$

Figure 9. $\mathrm{C}_{\mathrm{L}} \mathrm{danC}_{\mathrm{D}}$ with respect to AoA from $10^{\circ}$ to $45^{\circ}$ of all 3 additional models and a non-canard model of SBTF fighter configuration 


\subsection{Summary of the Research Results}

The maximum coefficient of lift in models that use originalbody is larger than the model with wall symmetry and without the fuselage. The $C_{L}$ value that occurs in the original fuselage model is around 1.20. The $C_{L}$ of the symmetric fuselage and without fuselage wall models are about 1.05 and 0.885 respectively. This condition can be seen from the formation of vortex cores in the main wing and fuselage vortex which is still visible in AoA $40^{\circ}$ which contributes to the addition of lift values.

Differences also occur in the location of the breakdown vortex above the canard and main wing on the aircraft model. The location of the vortex breakdown affects the lift force produced. The further the breakdown vortex location from the top of the wing, the $\mathrm{C}_{\mathrm{L}}$ value increases. In AoA $20^{\circ}$, the location of the vortex breakdown with the SBTF fighter model with original fuselage is still at $78.6 \%$ wing length, while for the symmetric fuselage and without fuselage wall models $27 \%$ and $98 \%$ respectively. Vortex breakdown location will be further with the model using original fuselage compared to models without fuselage and wall symmetric fuselage on low AoA, but at high AoA it is relatively the same.

In high AoA conditions, vortex cores and vortex breakdowns that occur above the wings of the original fuselage model and symmetric wall fuselage will tend to be attracted towards the fuselage. The higher the AoA, the vortex rolls up on the fuselage will be as strong as it will form, resulting in the reaction or incorporation of vortex cores in the canard and main wing with the fuselage vortex. In the original fuselage model, the process of combining vortex will be beneficial because it forms a blended body that creates negative pressure so that it increases the style of the gate. Whereas on the symmetric fuselage wall, the fuselage vortex interaction will cause negative pressure around the vertical wall. Unlike the fuselage model without fuselage, vortex cores are formedon edge along the LE.

From the research that has been carried out on an SBTF similar fighter model, some test data are obtained which show the performance and visualization results between the fighter models that have been tested. The results include; a) for the original model, $\mathrm{C}_{\mathrm{L}} \max$ is 1.200576 , on AoA $40^{\circ}$, and for both models with wall symmetry CL $\max$ is 1.080518 at $\mathrm{AoA}=35^{\circ}$, and models without fuselage $\mathrm{C}_{\mathrm{L}}$ max is 0.960460 at $\mathrm{AoA}=40^{\circ} . \mathrm{C}_{\mathrm{Lmax}}$ without canard is 1,112537 at $A o A=35^{\circ}$. The increase in $C_{D}$ value would increaseon every increase in $A o A$; this is due to the greater contact surface of the plane when AoA increases so that the drag force will increase.

Figure 7 demonstrates the eddy breakdown location of the AoA increase in each test model. At low angles, the original fuselage model has a vortex breakdown location that is farther than the symmetric fuselage and without fuselage walls, but at AoA the high breakdown vortex location is relatively the same.

\section{Conclusion}

From the research of the SBTF fighter, it was concluded that the influence of fuselage and canard on $\mathrm{C}_{\mathrm{L}}$ max test performance is that with the right fuselage design would enhance lifts, reduces aircraft drag, and it would affect the flow pattern around the wings.

The aircraft canard suspends the stallby returning the flow that has been turbulence, to the top of the wing which will be back laminar again. Therefore, the aircraftcan maneuver up to higherAoA without a stall. It is identified that canard and fuselage play significant roles on the design of a fighter. The design choice of the fuselage and the employment of canard are fundamental to support the ability of maneuver and agility of the fighter.

The flow velocity above the wing surface will be higher than the flow velocity below the wing. It will develop the rolled-up vortex from the tip of the wing to the downstream of the wing which in the middle part of the coil there is a vortex core which has the lowest pressure. This vortex core has a higher axial speed than the freestream speed. Thus, the vortex core makes negative pressure above the wing surface. The formation of a vortex core will cause the lift force to occur.

The maximum coefficient of lift in models that use original fuselage is larger than the model with wall symmetry and without the fuselage. The original fuselage model has a location of vortex burst that is more distance away than the symmetric fuselage and without fuselage walls. One of the functions of using canard on an aircraft is to increase lift on the aircraft and serves to delay the stall on the aircraft by firing a high-speed laminar flow vortex towards the wing so that it remains laminar. With the ability to maintain lift, the aircraft is able to maneuver up to a high AoA.

\section{Acknowledgments}

This research was funded by the Department of Mechanical \& Industrial Engineering, Universitas Gadjah Mada, Indonesia, under the contract 894/H1.17/TMI/LK/2017. The authors would like to express sincere gratitude to Prof. 
Dr. NoerIlman, Dr. Bramantya, and Dr. Suyitno for time spent in serious discussion, helpful suggestion, and useful conceptual contribution. We would like to thank also our students Farhan, Yogi, Wega, our laboratory staffs, Waji and Min, their help in construction work and conducting data management are gratefully acknowledged.

\section{References}

Abene, A. (2013). Visualisation of Vortex Structures Developed on the Upper Surface of Double-Delta Wings. Journal of Aeronautics \& Aerospace Engineering, 2(04), 4-7. https://doi.org/10.4172/2168-9792.1000118

Boelens, O. J. (2012). CFD analysis of the flow around the X-31 aircraft at high angle of attack. Aerospace Science and Technology, 20(1), 38-51. https://doi.org/10.1016/j.ast.2012.03.003

Cai, J., Tsai, H. M., Luo, S., \& Liu, F. (2011). Design of an Optimal Wing-Body Configuration to Delay Onset of Vortex Asymmetry. AIAA Journal, 49(1), 164-171. https://doi.org/10.2514/1.J050595

Chen, H., Pan, C., \& Wang, J. (2013). Effects of sinusoidal leading edge on delta wing performance and mechanism. Science China Technological Sciences, 56(3), 772-779. https://doi.org/10.1007/s11431-013-5143-3

Cobleigh, B. R., \& Delfrate, J. (1994). Water tunnel flow visualization study of a 4.4 percent scale X-31 forebody, (September).

del Pino, C., Parras, L., Felli, M., \& Fernandez-Feria, R. (2011). Structure of trailing vortices: Comparison between particle image velocimetry measurements and theoretical models. Physics of Fluids, 23(1), 1-12. https://doi.org/10.1063/1.3537791

Erickson, G. (1981). Water-Tunnel Studies of Leading-Edge Vortices, 19(6), 442-448.

Erm, L. P., \& Ol, M. V. (2012). An Assessment of the Usefulness of Water Tunnels for Aerodynamic Investigations, (August 2010).

Frate, J. H. Del. (1995). NASA Dryden Flow Visualization Facility NASA Dryden Flow Visualization Facility (No. H-1972, NASA Dryden Flight Research Center). Nasa Technical Memorandum. California.

Ghoreyshi, M., Cummings, R. M., Ronch, A. Da, \& Badcock, K. J. (2013). Transonic Aerodynamic Load Modeling of X-31 Aircraft Pitching Motions. AIAA Journal, 51(10), 2447-2464. https://doi.org/10.2514/1.J052309

Ghoreyshi, M., Korkis-kanaan, R., Jirásek, A., Cummings, R. M., \& Lofthouse, J. (2016). Simulation validation

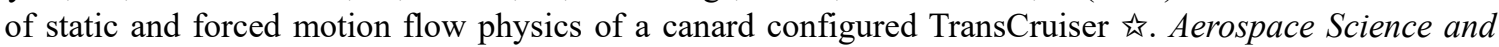
Technology, 48, 158-177. https://doi.org/10.1016/j.ast.2015.11.008

Guoqing, Z., Shuxing, Y., \& Yong, X. (2010). Investigation of Vortex Interaction in Canard-FSW Configurations Based on the Numerical Wind Tunnel Method. Chinese Journal of Aeronautics, 23(3), 312-319. https://doi.org/10.1016/S1000-9361(09)60221-1

Ito, Y., \& Iwashita, H. (2014). A Study on the Aerodynamic Properties of a Canard-Configuration WISES Highlights : 29th Intl Workshop on Water Waves and Floating Bodies, 29(5), 29-32.

Jin-Jun, W., \& Wang, Z. (2008). Experimental investigations on leading-edge vortex structures for flow over nonslender delta wings. Chinese Physics Letters, 25(7), 2550-2553. https://doi.org/10.1088/0256$307 \mathrm{X} / 25 / 7 / 060$

Jing, W., Yankui, W., \& Xueying, D. (2016). An experimental investigation on static directional stability. Chinese Journal of Aeronautics, 29(6), 1527-1540. https://doi.org/10.1016/j.cja.2016.10.008

Johnson, S. A., \& Fisher, D. F. (1990). Water-Tunnel Study Results of a TF / A = 18 and F / A=18 Canopy Flow Visualization.

Kwak, D., Nelson, R. C., Dame, N., \& Dame, N. (2010). Vortical Flow Control over Delta Wings with Different Sweep Back Angles Using DBD Plasma Actuators. In 5th Flow Control Conference (pp. 1-10). Chicago. https://doi.org/doi:10.2514/6.2010-4837

Lee, T., \& Su, Y. Y. (2012). Wingtip vortex control via the use of a reverse half-delta wing. Experiments in Fluids, 52(6), 1593-1609. https://doi.org/10.1007/s00348-012-1274-8

Lopes, V. M. L., \& Roberto da Mota Girardi. (2005). Analysis of The Aerodynamics Characteristics of a WingCanard Configuration With Canard Deflection Using Panel Method. Proceedings of COBEM 2005, 18th International Congress of Mechanical Engineering, (Figure 1).

Mahdi, M. (2015). Prediction of Wing Downwash Using CFD. In 3rd International Workshop on Numerical Modelling in Aerospace Sciences (Vol. 7, pp. 105-111). https://doi.org/10.13111/2066-8201.2015.7.2.10 
Miller, G. D., \& Williamson, C. H. K. (1997). Turbulent Structures in the Trailing Vortex Wake of a Delta Wing. Experimental Thermal and Fluid Science, 14(96), 2-8.

Owen, F. K., \& Peake, D. J. (2003). Vortex Breakdown and Control Experiments in the Ames-DrydenWater Tunnel, (November), 1-13.

Qu, Q., Chen, M., Liu, P., Guo, H., \& Qu, Q. (2015). Effect of Sideslip on High-Angle-of-Attack Vortex Flow over Close-Coupled Canard Configuration Effect of Sideslip on High-Angle-of-Attack Vortex Flow over CloseCoupled Canard Configuration, (October). https://doi.org/10.2514/1.C033305

Samimi, S., Davari, A. R., \& Soltani, A. M. R. (2013). Canard-Wing Interactions in Subsonic Flow*. Transactions of Mechanical Engineering, 37(M2), 133-147.

Schütte, A., Rein, M., \& Höhler, G. (2007). Experimental and numerical aspects of simulating unsteady flows around the X-31 configuration. In 3rd Inter Symp on Integrating CFD and Experiments in Aerodynamics 20-21 (pp. 1-16). https://doi.org/10.1243/09544100JAERO387

Shi, W., Deng, X. Y., Wang, Y. K., \& Tian, W. (2013). Interactions of Asymmetric Vortices over Chined Forebody / Wing Configuration at High Angles of Attack. Procedia Engineering, 67(mm), 317-327. https://doi.org/10.1016/j.proeng.2013.12.031

Sohn, Hwan Myong, \& Chang, W. J. (2010). Effect of a centerbody on the vortex flow of a double-delta wing with leading edge extension. Aerospace Science and Technology, 14(1), 11-18. https://doi.org/10.1016/j.ast.2009.11.004

Sun, D., Li, Q., \& Zhang, H. (2013). Detached-eddy simulations on massively separated flows over a 76/40 doubledelta wing. Aerospace Science and Technology, 30(1), 33-45. https://doi.org/10.1016/j.ast.2013.07.001

Sutrisno, Deendarlianto, Rochmat, T. A., Indarto, Wibowo, S. B., Iswahyudi, S., ... Erlambang, D. B. M. (2017). The Rolled-up and Tip Vortices Studies in the CFD Model of the 3-D Swept-Backward Wind Turbine Blades. Modern Applied Science, 11(12), 118. https://doi.org/10.5539/mas.v11n12p118

Sutrisno, Rochmat, T. A., Setyawan, B. W., Iswahyudi, S., Wiratama, C., \& Kartika, W. (2018). The Flow Visualization CFD Studies of the Fuselage and Rolled-up Vortex Effects of the Chengdu J-10-like Fighter Canard. Modern Applied Science, 12(2).https://doi.org/10.5539/mas.v12n2p148.

Vlahostergios, Z., Missirlis, D., Yakinthos, K., \& Goulas, A. (2013). Computational modeling of vortex breakdown control on a delta wing. International Journal of Heat and Fluid Flow, 39, 64-77. https://doi.org/10.1016/j.ijheatfluidflow.2012.12.002

Wibowo, S. B., Sutrisno, \& Rohmat, T. A. (2018). An Evaluation of Turbulence Model for Vortex Breakdown Detection over Delta Wing. Archive of Mechanical Engineering, $L X V(3)$, https://doi.org/10.24425/124489

Wibowo, S. B., Sutrisno, Rohmat, T. A., Anwar, Z., Syadi, F. R., Mahardika, R., \& Naufal, W. F. (2018). An investigation into the use of GAMA water tunnel for visualization of vortex breakdown on the delta wing. In 9th International Conference on Thermofluids (p. 050007). Yogyakarta, Indonesia: AIP Conference Proceedings. https://doi.org/10.1063/1.5049998

\section{Copyrights}

Copyright for this article is retained by the author(s), with first publication rights granted to the journal.

This is an open-access article distributed under the terms and conditions of the Creative Commons Attribution license (http://creativecommons.org/licenses/by/4.0/). 